\title{
Relation Between Heart Rate and Problem Behaviors
}

\author{
Rachel L. Freeman and Robert H. Horner \\ University of Oregon
}

Joe Reichle

University of Minnesota

\begin{abstract}
A new methodological approach for understanding self-injury, aggression, and property destruction exhibited by individuals with severe developmental disabilities was evaluated in this descriptive study. Measures of heart-rate changes before, during, and after episodes of problem behavior were obtained in real time. Unique patterns of heart rate and problem behavior were documented for each participant. Heart rate, identified as an indicator of negative arousal, was reliably associated with higher scores of perceived distress. These results indicate that further research is needed to examine the link between problem behavior and physiology. The study also suggests that physiological measurement can be included in the functional assessment process to further our understanding of the mechanisms underlying problem behavior.
\end{abstract}

Functional assessment technology has become a powerful tool used to discover the conditions under which a problem behavior is maintained (Carr, 1994; Homer, 1994). A large percentage of functional assessments result in the clear identification of social factors that mediate problem behavior (Iwata et al., 1994; Vollmer, Marcus, \& LeBlanc, 1994). However, other cases do not yield conclusive findings. In a recent summary of 152 functional analyses of self-injurious behavior (SIB), Iwata and his colleagues (1994) reported that $30 \%$ involved automatic reinforcement (sensory stimulation, pain attenuation, and undifferentiated high responding); that is, these $30 \%$ did not show sensitivity to socially mediated reinforcement (Vollmer et al., 1994). Derby et al. (1992) found that $34 \%$ of their clients engaged in problem behavior that appeared to be maintained by automatic/sensory consequences. These data suggest that in around $30 \%$ of instances, investigators using functional analysis were unable to identify a socially mediated function maintaining problem behavior. In many of these cases, the term automatic reinfo-rcement was used as a default hypothesis in the absence of positive experimental effect (Kennedy, 1994). This may place interventionists in a position where they are expected to identify effective interventions based on inconclusive assessment results (Vollmer et al., 1994).

Numerous investigators have hypothesized that biological variables may be a significant setting event or discriminative stimulus for problem behavior (Azrin, Hutchinson, \& Sallery, 1964; Carr, 1994; Gluck, Otto, \& Beauchamp, 1985; Romanczyk \& Mathews, in press). If this is true, incorporating psychophysiological measurement may represent a fruitful 
component of the functional assessment process (Romanczyk \& Mathews, in press). Romanczyk and his colleagues (Romanczyk \& Mathews, in press; Romanczyk, Gordon, Crimmins, Wenzel, \& Kistner, 1980) have been using psychophysiological monitoring to augment functional assessment of antecedent analyses. Romanczyk and Mathews proposed that in some cases "physiological events may be considered antecedents, determinants, concomitants, or the result of behavior" (manuscript p. 3). The relation between physiology and problem behavior also may be viewed from a respondent learning paradigm (Carr, 1994).

Physiological changes in an individual during the period in which he or she engages in problem behavior may increase the likelihood that respondent learning may have occurred in addition to any operant learning (Schwartz, 1989). Martin and Pear (1988), in discussing the relation between operant and respondent learning, asserted that any behavioral sequence is likely to include both types of learning. Romanczyk and his colleagues have proposed a model of SIB that combines operant and respondent components (Romanczyk, 1987, 1992; Romanczyk, Kistner, \& Plienis, 1982).

Romanczyk's (1992) operant-respondent model emphasizes arousal as an important maintaining fictor in the occurrence of SIB. According to this theory, initially SIB may be elicited by arousal. Over time, the environmental events present during the time of high arousal begin to shape and maintain the occurrence of SIB. In this model, SIB is an aversive event. The pain from self-injury causes an individual to become aroused and seek escape in order to reduce arousal. Under these conditions individuals engaging in SIB do not "want" to hurt themselves and are physiologically aroused when situations are presented that elicit SIB. This theory also suggests SIB may at times be preceded by an aversive emotional state. Self-injury is reinforced by staff restraint that concludes in the individual calming down and returning to physiological equilibrium. The link between physiological arousal and problem behavior needs greater documentation if we are to better understand this theory.

A number of researchers have proposed a relation between physiological arousal and a variety of problem behaviors, including self-injury (Frankel \& Simmons, 1976; Newsom, Can, \& Lovaas, 1977; Romanczyk, 1977; Romanczyk \& Goren, 1975). Methodological challenges have limited efforts to examine the relation between these variables (Romanczyk, 1992). Consequently, physiological measures have not yet been incorporated into functional assessment procedures, even though they have been described as an important area of research (Carr, 1994). Recent advances in psychophysiological measurement devices are now making it possible to explore the link between physiology and problem behavior (Romanczyk, 1992).

Because the etiology of problem behavior supports the influence of both biological and environmental factors (Carr, 1977; Guess \& Carr, 1991; Harris, 1992; Romanczyk, 1987; Schroeder \& Luiselli, 1992), some researchers have proposed that a more sophisticated as sessment approach that considers the interrelation of environmental and physiblogical factors related to problem behavior is needed (Guess \& Carr, 1991; Vollmer et al., 1994). Mace and Mauk (1999) have proposed that incorporating physiological measurement into the functional assessment process is imperative in order to fully understand and treat severe problem behavior. Although there are a variety of ways to record physiological arousal, heart rate is one of the few measures that can be used reliably in the natural environment.

The relation between stress and increases in cardiovascular function is now widely accepted in medical practice (Hassett \& Danforth, 1982). Heart-rate measurement is one of the most commonly used indices of arousal (Romanczyk, Lockshin, \& O'Connor, 1992), partly 
because it can be measured easily and accurately (Cacioppo \& Petty, 1982a; Turner, 1994). The cardiovascular system is responsible for major life support, controlling metabolic functions that include distributing oxygen to tissues, removing metabolic waste, controlling temperature, and balancing fluids and electrolytes (Obrist, 1982). Caution in interpreting heart-rate change is warranted because researchers must try to separate heart-rate responses associated with problem behavior from natural physiological and physical factors that systematically affect this measure (Tursky \& Jamner, 1982).

Although somatic activity (e.g., physical movement) is closely linked to heart rate (Obrist, 1982; Obrist, Webb, Sutterer, \& Howard, 1970), researchers investigating active avoidance demonstrated that participants placed in a situation in which they could actively avoid a threatening stimulus found that "active coping" resulted in increases in heart rate exceeding any possible metabolic demand (Obrist, 1976). In one experiment, participants who could avoid shocks showed greater increases in systolic blood pressure and both cardiac rate and performance compared to participants passively exposed to shocks (Light \& Obrist, 1980). In another experiment, participants showed greater in creases in heart rate when led to believe that they could avoid shock by modifying an undesignated bodily activity (Obrist, 1976).

When examining the interrelation of physiology and problem behavior, it is important to conduct studies in the natural environment. Historically, this was nearly impossible due to bulky and senstive equipment. Recent advances in measurement technology, however, allow reliable heartrate measures to be taken during dynamic activities in natural environments (Romanczyk et al., 1992). Heart-rate monitors such as the Polar Vantage XL have been developed for use in athletic training and research (Dobkin \& Pihl, 1992; Halle \& Gabler-Halle, 1989), and there is evidence of its reliability and validity (Leger \& Thivierge, 1988).

Fowles (1982) has described heart-rate measurement as a "noisy index of anxiety" (p. 113). Increases in heart rate can be attributed to many different variables, including mental effort, affective states, feeding, and physical exertion (Shapiro \& Reeves, 1982). As a result, additional information is needed to understand the relation between heart-rate increase and the occurrence of problem behavior. Cacioppo and Petty (1982a, 1982b) argued that physiological re sponses must be interpreted within the context of the individual's reportable state. Individuals with severe intellectual disabilities may not be able to verbalize positive or negative affective states; however, observers may be able to capture this phenomenological information effectively. The link between anxiety or other emotional states and heart rate in some cases also may be directly related to the occurrence of problem behaviors.

Patterns of rhythmic cycles in selfinjury have been reported by a number of investigators (Carlson, 1988; Lewis, MacLean, Johnson, \& Baumeister, 1981; Romanczyk et al., 1992; Romanczyk et al., 1980). Understanding these rhythmic cycles of arousal may lead to more effective medical treatment and behavior support strategies. For example, if physological arousal is higher at a certain time of day and an individual is more likely to engage in problem behaviors when heart-rate increases, more pleasurable or relaxing activities may be recognized to occur at these times.

Two hypotheses may explain the link between arousal and problem behavior (see Figure 1). In the first hypothesis, problem behavior serves as a discriminative stimulus for increases in arousal. In this scenario heart-rate increases would be expected to follow the occurrence of problem behavior. The second hypothesis suggests that some individuals may have increases in heart rate preceding and setting the stage for problem behavior. Individuals who consistently react to 
situations and events with increased physiological arousal preceding problem behavior may be more anxious, and this anxiety may be an establishing operation for problem behavior (Bijou \& Baer, 1961; Kantor, 1959; Wahler \& Graves, 1983).
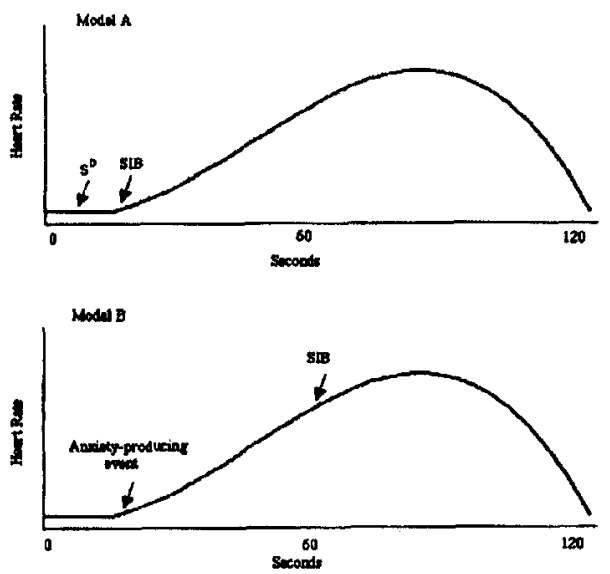

Figure 1. Models of arousal in relation to problem behavior.

In summary, the presence of heart-rate increase may be related to emotional lability (Shapiro \& Reeves, 1982), and this emotionality may lead to the occurence of problem behavior (Frankel \& Simmons, 1976; Newsom et al., 1977; Romanczyk, 1977; Romanczyk \& Goren, 1975). To better understand and treat problem behaviors such as SIB, professionals need a model that incorporates physiological measurement into the functional assessment process (Mace \& Mauk, 1999). The present investigation was designed to determine the feasibility of linking patterns of physiological arousal to problem behavior in real time and in the natural environment.

\section{Method}

\section{Participants}

Participants were 2 men with severe intellectual disabilities and multiple problem behaviors. They lived together in a twobedroom home in a community setting. Archie was a 33-year-old man diagnosed with (a) severe mental retardation, (b) congenital cataracts resulting in total vision impairment, and (c) grand mal seizures. Seizure activity was partially controlled by Depakote, adminis tered at a dose of 1,500 $\mathrm{mg}$ per day. Archie received $7.5 \mathrm{mg}$ of clorazepate dipotassium daily for muscle tremors and "twitches." Carbamazapine (400 $\mathrm{mg}$ ) was withdrawn the month prior to the study. There were significant variations in Archie's sleep patterns, which were reported to be cyclical in nature and thought to affect his mood. Archie's problem behaviors included (a) biting his own wrist; (b) aggression towards others by striking out with one hand or grabbing with the intent to bite; and (c) disruptive behaviors, such as throwing objects across the room, pushing away task-related objects, and standing up in the middle of an activity that required sitting. Through a functional assessment conducted by his residential service provider following interview and direct observation procedures recommended by O'Neill et al. (1997), these behaviors were identified as part of the same response class, with the hypothesized function being escape from demanding tasks. The purpose of the functional assessment was to generate a clinical hypothesis regarding the function of Archie's problem behavior, although this hypothesis was not confirmed through functional analysis. Common tasks that Archie naturally avoided included shaving and brushing his teeth. Both tasks required staff assis tance to complete.

Sean, a 38-year-old man also diagnosed with severe intellectual disabilities, had impaired vision, although he was able to see people and objects and move around new environments with caution. Sean did not receive any medication; however, he suffered from rectal prolapse problems and/or hemorrhoids. A dose of $80 \mathrm{mg}$ of simethicone 
was given up to four times daily for gas when Sean suffered from "agitations" relating to physical discomfort presumed to be due to gas pain. His problem behaviors included (a) rhythmic, repetitive head hits with the open palm of his hand and with a closed fist; (b) banging or slapping his chest, legs, or walls and other surfaces with an open palm or closed fist; and (c) biting his index finger, causing some redness. A functional assessment similar to that implemented with Archie indicated that Sean's problem behaviors served multiple functions. Direct observation data indicated that this behavior was associated with escape from activities that were related to staffs provision of assistance. In addition, Sean engaged in problem behavior to avoid holding objects in his hands. Staff members hypothesized that agitation and problem behaviors were more likely when Sean was experiencing physical pain due to stomach and bowel problems. We were unable to empirically validate this nonsocially mediated function.

\section{Tasks/Settings}

The study took place within the participants' home. Activities were selected to fit within regular daily schedules. Archie had a very structured morning that included shaving and tooth-brushing routines, which were associated with problem behaviors. Sean's daily schedule was more variable than was Archie's. Examples of the activities Sean engaged in included doing laundry, feeding the cat, and playing the drums. His activities did not occur in a predictable sequence and were not the same from day to day.

\section{Procedure}

The design of the study was descriptive. Data on the covariation and rate of problem behaviors, heart rate, and activities in real time were collected. A baseline rate of problem behaviors was obtained to assure that wearing the heart-rate monitor was not associated with any increases in rate of problem behaviors. Participants were videotaped wearing the heart-rate monitor for 20 to 60 minutes each day during baseline and heartrate data-collection phases. Archie was videotaped during baseline for 6 days and Sean, for 5 days. Once baseline data collection was completed, the heart-rate monitor was included during videotaped sessions. The recording sessions were not meant to sample different heart rate times in relation to problem behavior throughout the day. Instead, a fixed time period was identified during functional assessment and selected based on the following characteristics: problem behaviors were likely to occur, the activities occurring were highly predictable, and the activities required a relatively consis tent level of motor movements. Time of day chosen for videotaping each participant remained constant to enable us to account for any changes in heart rate due to circadian cycles throughout the day. Taping occurred three to five times a week for Archie for a total of 27 sessions. Sean's behavior was monitored a total of 18 days.

\section{Measurement}

Heart rate. Participants wore a Polar Vantage XL Heart Rate Monitor that was activated at the same time that videotaping started. This monitor uses electrocardiogram measurement to detect electrical impulses of the heart at the chest wall. A chest belt with a transmitter picks up the electrical signal of the heart and transmits the data without use of wires to a watch that stores the information for evaluation. Average heart rate was recorded every 15 seconds, transmitted to a watch, and recorded in memory to be retrieved at a later time via Polar's software program. Partici pants wore the watch in a fanny pack around the waist in order to avoid equipment damage or possble injury.

Problem behavior. A video camcorder was used to tape observations. These video- 
tapes were coded by data collectors using a video monitor and two desktop computers. Portable Computer System for Observational Use software was used to record data from videotaped sessions (Karsh, Repp, \& Ludewig, 1989; Repp \& Karsh, 1994). Each key stroke is recorded in real time at 1-second intervals. Codes were developed to record behaviors and activities of interest. Observers touched the key corresponding to a coded behavior.

For Archie, codes were developed for problem behaviors that included self-bites, disruptive behaviors, and aggression. Sean's problem behaviors included finger bites, medium-to-hard head hits, and banging/ slapping self or objects. For both participants, on-set, off-set, and duration of activities were coded.

Two Independent observers recorded $30 \%$ of baseline sessions and $34 \%$ of all sessions for Archie, Interobserver agreement was calculated using Cohen's Kappa, a statistic that indicates the proportion of agreements corrected for chance agreements (Cohen, 1960; Hartman, 1977). Archie's Kappa scores during baseline were +1.00 for self-bites, +.98 for disruptive behavior, and +.98 for aggression. Kappa values during the heart-rate monitoring stage for Archie were +1.00 for self-bites, +.99 for disruptive behaviors, and +1.00 for aggression. Interobserver agreement for Sean was collected on $33 \%$ of all baseline sessions and $32 \%$ of sessions during the heart-rate monitoring stage. Baseline Kappa values for Sean were +.99 for hard head hits and +.98 for banging/slapping self or objects. No finger bites occurred during baseline sessions. Kappa scores during the heart-rate monitoring stage were +1.00 for hard hits, +1.00 for finger bites, and +.99 for disruptive behavior.

Behavior state. Increases in heart rate can be attributed to many different variables, which makes heart-rate measurement alone difficult to interpret. For this reason, a scale measuring perceived level of distress was included to discriminate aversive and nonaversive states. A 4point Likert-type scale was created by building upon the behavior state codes used in Project ABLE (Analyzing Behavior State and Learning Environments Profile) developed by Ault, Guy, and Guess (1993) and Ault, Guy, Guess, Bashinski, and Roberts (1995). The scale was designed to identify whether participants were perceived to be in distress or were in a low distress state. Coders viewed video clips and rated them using the 4point distress scale, with 1 indicating low distress (sitting quietly, making happy sounds, no signs of agitation, low intensity self-injury) and 4 indicating high levels of dis tress (moaning, loud vocalizations lasting a long time in duration, high intensity self-injury present). After viewing the tape, coders gave a global distress score for the clip based on the frequency and intensity of problem behaviors and verbal protests.

For both participants, video clips used in the behavior state analysis were collected for each 15-second interval in which a problem behavior occurred. In addition, the 15-second interval preceding and 15-second interval following each targeted problem behavior were analyzed. Once coders judged the level of distress observed when participants were engaging in problem behavior, they assessed the level of distress during periods of time when no problem behaviors occurred. A 90-second period with no problem behaviors was taken from each session previously analyzed and was separated into six 15 -second intervals for coders to rate. Finally, 30-second time clips were taken from previously analyzed data that showed heart-rate increases but no problem behaviors. These clips were used to assess any differences between levels of distress when heart-rate increased and problem behaviors occurred versus heart-rate increases in the absence of any problem behavior.

Behaviors identified for Archie's coding were self-bites. Every fourth self-bite from the 27 sessions was analyzed for behavior state, resulting in a total of 43 occurrences. A total of 27 occurrences contained no problem behaviors. Sixteen pairs of 15 -second inter- 
vals representing a jump in heart rate greater than one standard deviation $(S D)$ were recorded. Every incidence of Sean's finger bites was analyzed, resulting in 76 occurrences. Due to the very high frequency of Sean's head hits, it was not possible to analyze every occurrence of this problem behavior. As a result, 2 of his head hits were randomly selected from each session and rated for level of distress, resulting in a total of 36 occurrences. Thirty-three occurrences of 90second periods and 22 occurrences of 30second pairs, representing a jump in heart rate with no problem behaviors, were collected for Sean.

Interobserver agreement for behavior state coding was calculated by dividing the number of occurrence only agreements by the number of agreements plus disagreements and multiplying by $100 \%$. All categories of behavior state clips were combined (e.g., 15-second clips before, during, and after individual behaviors; 30 seconds of heart-rate increase/no problem behavior; and $90 \mathrm{sec}$ onds/no problem behavior) for overall average interobserver agreement. For Archie, independent observers coded $33 \%$ of self-bite behavior state clips. Interobserver agreement on the distress scale was $88 \%$ (range $=$ $79 \%$ to $96 \%$ ). Independent observers recorded $34 \%$ of all clips for Sean's finger bites and 33\% of all head hit clips. The overall average agreement total for Sean was $89 \%$ (range = $77 \%$ to $100 \%$ ).

\section{Analysis Procedures}

The visual analysis of data provided information regarding sensitivity of the measurement procedures and the relation of heart rate and problem behaviors for each participant. Sequential analysis procedures for this descriptive study were used to assess conditional probabilities of heart-rate change and problem behavior given predictor conditions (Bakeman \& Gottman, 1986; Gottman, 1981; Gottman \& Roy, 1990).
Specific procedures for the analysis of each research question are d escribed in this section.

Heart-rate change as a sensitive measure of physiology. A major focus of the study was to address the extent to which heartrate patterns could be measured with sufficient sensitivity to index changes in arousal level that were linked with environmental events. Heart-rate levels with enough stability were needed to serve as baselines for comparison during changes in behavior states in order to demonstrate sensitivity. Stability, in this case, was defined as heart-rate patterns that demonstrated a low rate of variability. In addition, the patterns observed during behavior state changes had to be distinct in onset and offset, allowing for time-based sequential analysis.

To evaluate the heart-rate data, we transferred the files on the Polar Vantage XL watch to IBM compatible desktop computers using Polar Vantage XL soft ware. The result was an ASCII file list of heartbeats per minute every 15 seconds and a graphic display of each 15-second interval score for a session. These data were mapped onto a common time scale to allow visual comparison of heart rate and problem behaviors. Figure 2 shows an example of heart rate and problem behaviors. The next step was to analyze the data using sequential analysis procedures.

Relation between heart rate and problem behaviors. To link heart-rate increases to problem behavior, we needed an operational definition of heart-rate increase and rules for sequential analysis. A heart-rate increase was defined as any increase between two 15.second intervals greater than or equal to one average $S D$ for each participant. The average $S D$ for each participant was obtained by calculating the mean of the $S D s$ for all sessions. For Archie, any heart-rate increase of 6 heartbeats/minute was identified as a significant jump, whereas Sean's significant jump in heart rate was 7 heart beats/minute. 


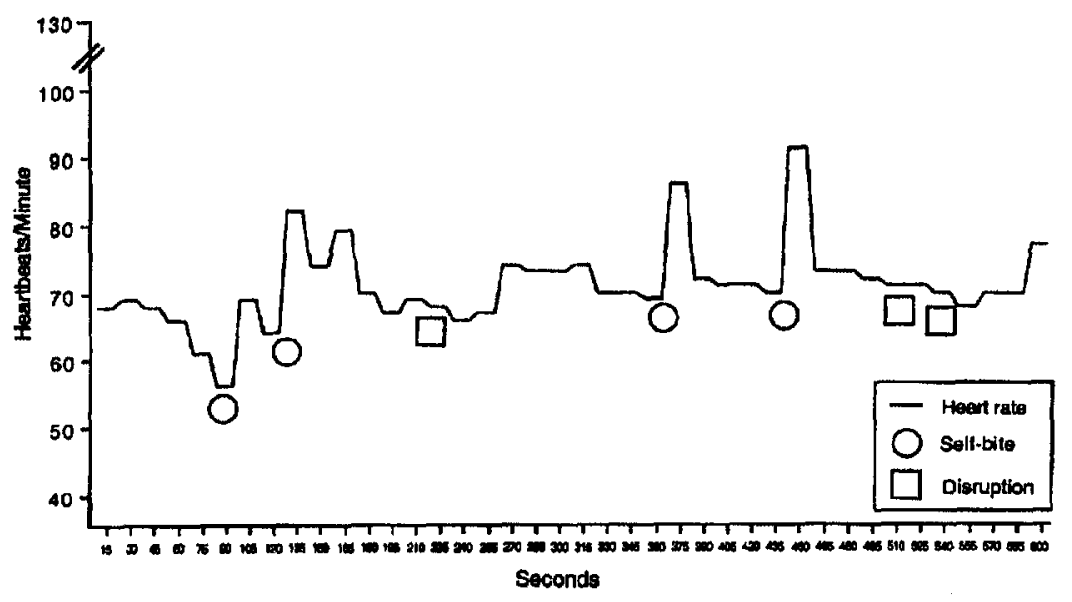

Figure 2. Heart-rate for Archie, calculated every 15 seconds, and the moment of occurrence for instances of selfbite and disruption.

The temporal link between heart-rate change and problem behavior was calculated by comparing (a) the probability that heart rate would increase one SD or more given the occurrence of a problem behavior (e.g., $\mathrm{P}$ [heart-rate increase/ " $\mathrm{X}$ " behavior]) with (b) the probability that heart rate would increase even though the problem behavior did not occur (e.g., $\mathrm{P}$ [heart-rate increase/No "X" behavior] ).

As a means of evaluating the significance of an observed frequency (conditional probability), a comparison to some set of expected frequencies is needed (Bakeman \& Gottman, 1986). These frequencies are expected because they are based upon assumptions that were made beforehand. The base rate probability used in this study originated from the assumption that heart rate would not increase significantly during intervals that had no problem behaviors. Therefore, when examining conditional probabilities, we expected that the probability of a heart-rate increase given the occurrence of a problem behavior would re sult in higher scores when compared to the base rate probability that heart rate would increase given no problem behaviors.

The heart -rate and problem behavior data streams were analyzed using SAS software (Bynum et al., 1995). Problem behavior occurring within the corresponding 15second interval of heart rate was identified. When one or more targeted behaviors occurred in a 15-second interval, the SAS program determined whether heart-rate change was greater than one $S D$ in the preceding or following interval. Figure 3 is a visual demonstration of how each problem behavior was aligned with heart rate. The triangular symbol in this figure represents a problem behavior. Short horizontal lines are representative of a 15-second heart-rate interval. The triangle that occurred during Interval 3 was compared to the next interval.

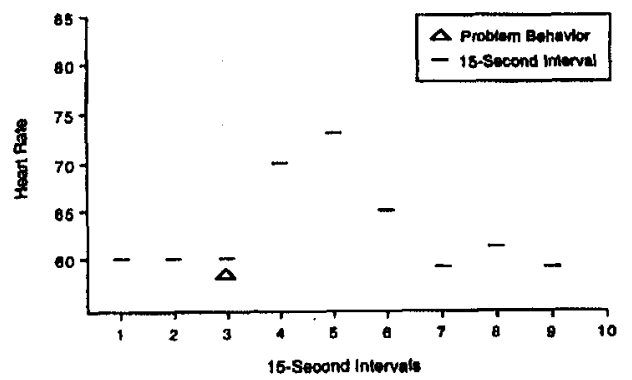

Figure 3. Analyzing heart-rate increase given problem behavior. 
An increase over one $S D$ was counted as a heart-rate increase following problem behavior.

The specific targeted behaviors were selected when they occurred alone or concurrently with other problem behaviors. All intervals with problem behaviors were combined for that session, creating a four-fold figure presenting probability results. Table 1 displays the interaction of heart-rate increase and problem behavior.

\begin{tabular}{|c|c|c|c|}
\hline Increase & $\begin{array}{l}\text { Intervals with } \\
\text { no problem } \\
\text { behavior }\end{array}$ & $\begin{array}{l}\text { Intervals with } \\
\text { problem } \\
\text { behavior }\end{array}$ & Total \\
\hline No heart-rate increase & 135 & 13 & 148 \\
\hline Heart-rate increase & 12 & 10 & 22 \\
\hline \multirow{2}{*}{ Total } & $(.08)$ & $(.43)$ & \\
\hline & 147 & 23 & \\
\hline $\begin{array}{l}\text { Note. Probability o } \\
\text { nonoccurrence of pro } \\
\text { probability of heart-ra } \\
\text { problem behavior. }\end{array}$ & $\begin{array}{l}\text { f heart-rate } \\
\text { oblem behavio } \\
\text { te increase give }\end{array}$ & $\begin{array}{l}\text { Increase given } \\
\text { i compared to } \\
\text { en the occurrenc }\end{array}$ & $\begin{array}{l}\text { the } \\
\text { o the } \\
\text { ce of }\end{array}$ \\
\hline
\end{tabular}
significance of the probabilities. A z-score binomial test was used to test for significance between the conditional probability of interest and the base rate probability (Bakeman \& Gottman, 1986) because z scores are easily understood and intepreted and have been used by others when discussing sequential analysis (Allison \& Likert, 1982; Bakeman \& Gottman, 1986).

Relation between average heart-rate and problem behavior. Differences found in Archie's level of problem behavior during high versus low average heart-rate days became apparent when visual analysis was conducted. At the extreme ends of the average heart-rate days, the results showed clear differences in the level of problem behavior. Heart-rate averages in the middle ranges, however, were more variable. In order to determine clear patterns, we separated the data from the 9 highest and 9 lowest average heart-rate days and recalculated the conditional probabilities for each group.
The assumption was that there would be significant differences between conditional probabilities in the 9 highest versus the 9 lowest average heart-rate days. A z-score test comparing the probability of heart-rate increase given " $\mathrm{X}$ " behavior during the 9 highest average heart-rate days and the probability of heart-rate increase given " $\mathrm{X}$ " behavior during the 9 lowest average heartrate days was calculated.

\section{Results}

\section{Heart-Rate Preceding Problem Behavior}

Table 2 presents Archie's data across 26 sessions. A significant increase in heart rate (e.g., mean of the SDs for all sessions) for Archie occurred with an increase of 6 heartbeats per minute. Prior functional assessment indicated that Archie's problem behaviors, including self-bites, aggression, and disruptive behaviors, were maintained by escape from demands.

Table 2, which shows how frequently Archie's heart rate increased in the interval preceding a problem behavior, represents the overall probability of heart-rate increase preceding problem behavior from all of Archie's sessions. Results show a low likelyhood of heart-rate increase in the 15 seconds preceding problem behavior. The low probability of heart-rate increase given no self-bite, no disruption, no aggression, or no problem behaviors indicates that there is little difference between the base-rate probabilities and the probability of heart-rate increase given a problem behavior.

A significant increase in heart rate for Sean occurred with an increase of 7 heartbeats per minute (an average of the $S D s$ for each of the 18 sessions included in the analysis). Figure 4 shows a visual pattern of the relation of heart rate to head hits, finger bites, and bang/ slaps. Finger bites and bang/slaps occurred before and during periods of high agitation. 
Table $\hat{2}$

Probability of Heart-Rate Increase Preceding and Following Problem Behavior for participants

\begin{tabular}{|c|c|c|c|c|}
\hline \multirow[b]{4}{*}{ Behavior } & \multicolumn{4}{|c|}{ Problem behavior } \\
\hline & \multicolumn{2}{|c|}{15 seconds before } & \multicolumn{2}{|c|}{15 seconds following } \\
\hline & $\overline{\text { Heart-rate }}$ & & Heart-rate & \\
\hline & Increase & $\mathrm{n}$ & Increase & $\mathrm{n}$ \\
\hline \multicolumn{5}{|l|}{ Archie } \\
\hline Self-bile & .11 & 130 & $41 \bullet$ & 128 \\
\hline Disruption & .08 & 90 & .08 & 90 \\
\hline Aggression & .13 & 47 & $.45^{\prime}$ & 47 \\
\hline No self-bite & .10 & 2,184 & .09 & 2,186 \\
\hline No disruption & .10 & 2,281 & .10 & 2,261 \\
\hline No aggression & .09 & 1,769 & .10 & 1,769 \\
\hline No problem behavior & .09 & 1,653 & .07 & 1,666 \\
\hline \multicolumn{5}{|l|}{ Sean } \\
\hline Hard hit & .08 & 299 & .08 & 299 \\
\hline Finger We & .05 & 19 & $.53^{-}$ & 19 \\
\hline Bang/slap & .08 & 49 & $.18 * *$ & 50 \\
\hline No hard hit & .08 & 2,086 & .08 & 2,088 \\
\hline No finger bite & .07 & 2,231 & .07 & 2,231 \\
\hline No bang/slap & .07 & 2,110 & .07 & 2,109 \\
\hline No problem behavior & .07 & 1.838 & .07 & 1.820 \\
\hline
\end{tabular}

Note. $\mathrm{n}=$ frequency of 15 -second Intervals. A significant Increase In heart rate is defined as the average of the We of all sessions. All heart rate jumps are considered to be following or preceding a behavior if they occur In the 15 -second interval after or before the Interval occurs.

${ }^{*} \mathrm{p}<.001, \mathrm{P}$ (heart -rate Increase/selfbite) compared to $\mathrm{P}$ (heart -rate increase/no problem behavior) for Archie; $\mathrm{p}<.001, \mathrm{P}$ (heart rate increase/ finger bite) compared to $\mathrm{P}$ (heart -rate Increase/no problem behavior), $\mathrm{P}$ (heart -rate Increase/bang/slap) compared to $\mathrm{P}$ (heartrate Increase/no problem behavior) for Sean.

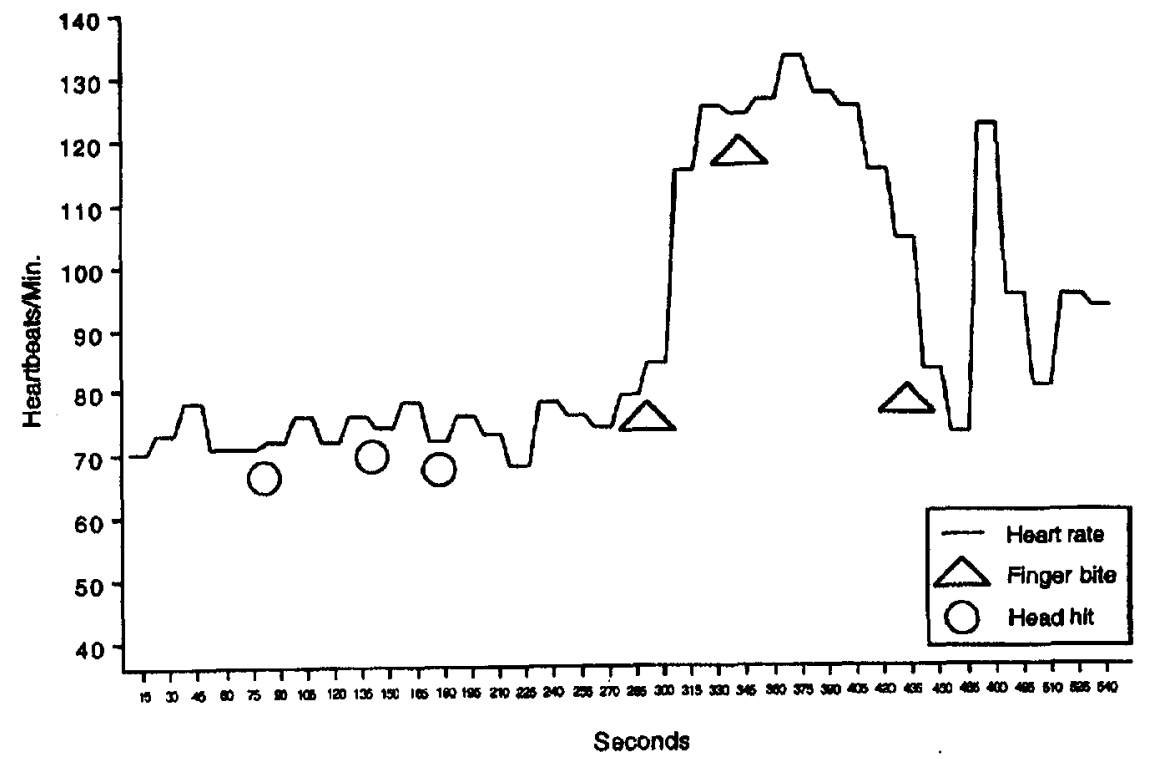

lifgure 4. Heart rate for Sean, calculated every 15 seconds, and the moment of occurrence for instances of finger bite and head hit. 
Hard hits, however, do not show this pattern. An initial analysis indicated that it was just as likely that there would be an increase in heart rate preceding finger bites and bang/slaps even though the pattern seen in Figure 4 indicates that heart rate increased after problem behavior.

Sean's finger bites and bang/slaps were reanalyzed by counting the first finger bite and bang/slap in a cluster and recording heart rate 15 seconds before and after the behavior. The next cluster began after 1 minute of no finger bites or bang/slaps. We analyzed Scan's hard hits by identifying each 15-second interval with behavior and the intervals preceding and following. The data presented in Table 2 represent the visual pattern from Figure 4. As shown in the table, Sean's frequency of heart-rate Increase preceding problem behavior is similar to Archie's. The probabilities of a heart-rate increase given hard hits, finger bites, and bang/slaps were all slightly lower than that observed for Archie.

\section{Heart Rate Following Problem Behavior}

Archie's data (see Table 2) show one of the unanticipated findings of the study. The three problem behaviors are part of a common response class identified as operant in nature. Although the behaviors appear roughly equal in physical exertion, heart rate was more likely to increase following a selfbite (.41) than a disruption (.08). Aggressive behaviors, which were concurrent with selfbites, had a higher probability of heart rate increase (.45).

Table 2 also shows Archie's base-rate probabilities. Stable patterns of heart-rate increase following and preceding no problem behaviors are evident. There were significant differences, $p<.001$, between the probability of heart-rate increase given selfbite and the probability of heart-rate increase given no problem behaviors. The probability of heart-rate increase following aggressive behavior compared to no pro-blem behavior was also significant.

Sean's data in Table 2 show a corresponding discovery. The three problem behaviors listed for him were determined to be part of a common response class. Prior functional assessment indicated that his problem behaviors had multiple functions: to escape from demands or activities and for automatic sensory reasons. In this case, as can be seen in the table, the behavior requiring the most physical exertion-hard hits -had the lowest probability of heart-rate increase. The behavior requiring the least amount of physical exertion-finger bites-had the highest probability of heart-rate Increase. Bang/slaps, which are roughly equal in physical exertion to hard hits, also had a higher probability of heart-rate increase than hard hits.

Sean's base-rate probabilities are also presented in Table 2. The probabilities of heart-rate increase given no hard hits, no finger bites, and no bang/slaps were exactly the same in the following interval as they were in the preceding interval, indicating the stability of base rates. There was a significant difference between the probability of heart-rate increase given finger bites and no problem behavior. The probability of heart-rate increase given bang/slaps versus no problem behavior was also significant.

\section{Absolute Heart Rate}

Another unanticipated discovery provides evidence of an abnormal cyclical pattern in heart rate for Archie. Whenthe study began, Archie's average heart rate was 60 beats per minute. Figure 5 shows an increase in average heart rate from 60 beats per minute to an average of 111 beats per minute over a 9-day period. Archie was videotaped at the same time every morning in a very structured routine, eliminating the possibility of heart-rate increase due to circadian rhythm or an unknown activity. No changes in physical exertion were introduced in Archie's activities. 


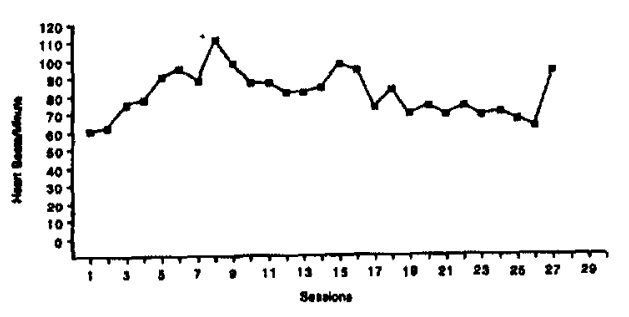

Ftoure 5. Archie's averace heart tate.

Level of problem behaviors changed with high versus low average heart-rate days. When Archie's average heart rate was low, there were higher levels of problem behavior compared to when his average heart rate was higher. Table 3 shows the probability of heart-rate increase given problem behaviors during Archie's 9 lowest and 9 highest average heart-rate days. When the data were separated, results indicated Archie's disruptive behaviors clustered, showing a high probability of heart-rate increase given disruptive behavior in both preceding and following intervals. We reanalyzed disruptive behaviors by counting the first disruption in a duster and recording heart rate 15 seconds before and after the behavior. The next cluster began after 1 minute of no disruptions.

The probability of heart-rate increase preceding problem behavior did not change across heart-rate levels. Differences in the frequency of heart-rate increase following problem behavior can be seen in Table 3 . When Archie's average heart-rate was low, he was more likely to have an increase in heart rate following self-bite and disruptive behavior. His overall affect during this time showed high levels of frustration and fatigue. During the 9 highest average heart-rate days, Archie's frequency of heart-rate increase given self-bite and disruptive behavior was lower. Self-bites occurred on only 3 out of 9 of the 9 lowest average heart-rate days. Archie appeared overexcited and happy during high average heart-rate days. Three seizures occurred during the same day as the study, all of them during high average heart-rate days, indicating Archie's seizure activity may be influenced by heart rate.

As can be seen from Table 3, there was a significant difference between the probability

Table 3

Probability of Heart-Rate Increase Preceding and Following Problem Behavior Separated by the Average

Heart-Rate Days for Archie

\begin{tabular}{|c|c|c|c|c|}
\hline \multirow[b]{3}{*}{ Behavior } & \multicolumn{4}{|c|}{ Problem behavior } \\
\hline & \multicolumn{2}{|c|}{15 seconds before } & \multicolumn{2}{|c|}{15 seconds following } \\
\hline & $\begin{array}{l}\text { Heart-rate } \\
\text { increase }\end{array}$ & $\mathrm{n}$ & $\begin{array}{l}\text { Heart-rate } \\
\text { increase }\end{array}$ & $\mathrm{n}$ \\
\hline \multicolumn{5}{|l|}{9 lowest days } \\
\hline Self-bite & .11 & 28 & $.57^{\prime}$ & 28 \\
\hline Disruption & 0.00 & 32 & $38^{\prime}$ & 32 \\
\hline No self-bite & .09 & 923 & .06 & 924 \\
\hline No disruption & .10 & 1,06 & .09 & 1,069 \\
\hline No problem behavior & .09 & 894 & .05 & 896 \\
\hline 9 highest days & 20 & 5 & .33 & 6 \\
\hline Self-hite & .20 & & & \\
\hline $\begin{array}{l}\text { Disruption } \\
\text { No self-bite }\end{array}$ & .08 & $\begin{array}{r}66 \\
708\end{array}$ & .14 & 609 \\
\hline No disruption & .13 & 659 & .12 & 659 \\
\hline No problem behavior & .09 & 603 & .09 & 709 \\
\hline
\end{tabular}

Note. $\mathrm{n}=$ frequency of 15 -second intervals. A significant increase in heart rate is defined as the average of the SDs of all sessions. All heart-rate jumps are considered to be following or preceding a behavior if they occur in the 15-second interval after or before the Interval occurs. $\mathrm{p}<.001$, P (heart-rate Increase/self-bite) during low average heart-rate days compared to P (heartrate Increase/selfbite) during high average heart-rate days, $\mathrm{P}$ (heart-rate increase/disruption) during low average heart-rate days compared to $\mathrm{P}$ (heart-rate Increase! disruption) during high average heart-rate days. 
probability of heart-rate increase following self-bite for the 9 highest compared to the 9 lowest average heart-rate days. Disruptions during the 9 lowest average heart-rate days were also significantly different from the 9 highest average heart-rate days.

Figures 5 and 6 show Archie's heart rate and probability of heart-rate increase following and preceding self-bites on each day. The dynamic nature of Archie's problem behavior is evident. During February, the level of Archie's problem behavior was high; however, the probability of heart-rate increase following self-bite was low. By March, Archie's heart-rate average had decreased, frequency of self-bites increased, and the probability of heart-rate increase following self-bite became consistently higher. A key finding is the dynamic change in Archie's level and frequency of heart rate increase given problem behavior, even though the function of his problem behaviors has been identified as operant in nature.

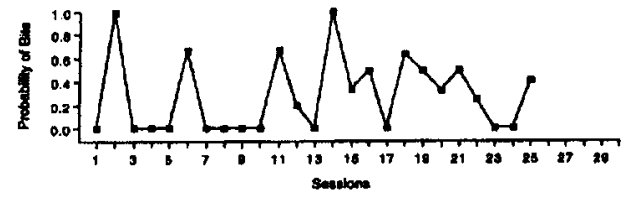

Figure 6. Archic's probability data.

\section{Discussion}

A major objective for building a body of research examining the link between physiology and problem behavior is documentation that measurement of physiology in real time and in real contexts can be accomplished with sufficient sensitivity to index functional changes. One contribution of this study was the documentation that heart rate and problem behavior can be measured accurately, allowing for assessment of covariation between variables. A second contribution is the evidence that heart rate can be measured with enough sensitivity to be of value in clinical environments. When heart rate and the occurrence of problem behavior were combined, a visual analysis of each session showed unique patterns of heart rate and problem behavior for each participant.

A third contribution of the study is the sequential analysis approach used to document the relation of heart rate and problem behavior described in Figure 1. The heart rate and continuous behavior recording data streams were compared so that a problem behavior occurring within the corresponding 15 second interval of heart rate could be identified. Increases in heart rate preceding and following 15-second intervals were determined for each session. Sessions were then combined to provide an overall probability.

Several limitations within the present study must be taken into consideration when reviewing the results. Some of these limitations are standard challenges to single participant descriptive research. Other limitations are unique to physiological measurement strategies.

The small participant pool restricts generalization of the findings. In fact, given the nature of the study, unique patterns of heart rate were expected to occur. Further research is needed, however, to explore the measurement of heart rate and problem behavior as well as to understand what similarities and differences exist across individuals with respect to heart rate.

Because this was a descriptive investigation, many uncontrolled variables may have been affecting behavior, which would make definitive conclusions about the results impossible. Conducting research in natural environments rather than laboratory settings increases external validity but raises problems with respect to internal validity. There are a number of uncontrolled variables that can occur due to environmental changes, such as activities occurring immediately before or after the study, changes in schedule, and sleeping cycles. 
With physiological measurement, internal factors may also contribute to extraneous variability. Heart rate Is influenced by physical exertion, eating, mental effort, positive affective states, sleep cycles, and respiration. The fact that most problem behaviors naturally involve some physical effort adds to the difficulties in the interpretation of level of distress. Heart rate increase followed problem behaviors for both participants, which could be interpreted as supporting the cardiacsomatic coupling theory.

In summary, the information reflected in this study represents a first step towards developing a methodology that can incurporate physiological measurement into the functional assessment process. One of the most valuable contributions of this investigation has been the collection of data in real time and in the natural environment because traditionally participants with disabilities are brought to a clinical settings and often have to be physically or chemically restrained in order to obtain data on their physiological status. Growing technological advances will no doubt produce other physiological devices that can be used in the natural environment without a lot of inconveniences. The possibility of com prehensive physiological assessment for individuals with severe problem behavior in their natural environment is now becoming a reality. Including physiological measurement in the functional assessment process holds great potential utility for both clinical and theoretical applications.

\section{References}

Allison, P. D., \& Likert, J. K. (1982). Analyzing sequential categorical data on dyadic interaction: A comment on Gottman. Psychological Bulletin, 91, 393-403.

Ault, M. M., Guy, B., \& Guess, D. (1993). Project ABLE manual: Analyzing behavior state and learning environments profile. Lawrence: University of Kansas, Department of Special Education.

Ault, M. M., Guy, B., Guess, D., Bashinski, S., \& Roberts, S. (1995). Analyzing behavior state and learning environments: Application in instruc-tional settings. Mental Retardation, 33, 304-316.

Azrin, N. H., Hutchinson, R. R., \& Sallery, S. D. (1964). Pain aggression toward inanimate objects. Journal of the Experimental Analysis of Behavior, 17, 223-228.

Bakeman, R., \& Gottman, J. M. (1986). Observing interaction: An introduction to sequential analysis. Cambridge: Cambridge University Press.

Bijou, S. W., \& Baer, D. M. (1961). Child development I: A systematic and empirical theory. Englewood Cliffs, NJ: Prentice Hall.

Bynum, R. A., Cybrynski, M. J., IaBarr, J., Marion, M. S., Prabju, S. S., Rodriguez, R. N., \& Tobias, R. D. (1995). SAS/QCII software: Usage and reference (Vol. 6). Cary, NC: SAS Institute.

Cacioppo, J. T., \& Petty, R. E. (1982a). A biosocial model of attitude change. In $\mathrm{J}$. T. Cacioppo \& R. E. Petty (Eds.), Perspectives in cardiovascular psycho-physiology (pp. 151-188). New York: Guilford Press.

Cacioppo, J. T., \& Petty, R. E. (1982b). Editor's overview. In J. T. Cacioppo \& R. E. Petty (Eds.), Perspectives in cardiovascular psychophysiology (pp. 1-2). New York: Guilford Press.

Carlson, N. R. (1988). Foundations of physiological psychology. Boston: Allyn \& Bacon.

Carr, E. G. (1977). The motivation of self-injurious behavior: A review of some hypotheses. Psychological Bulletin, 84, 800-816.

Carr, E. G. (1994). Emerging themes in the functional analysis of problem behavior. Joumal of Applied Behavior Analysis, 27, 393-399.

Cohen, J. (1960). A coefficient of agreement for nominal scales. Educational and Psychological Measurement, 20, 37-46.

Crane, A. A., \& Joyce, B. G. (1991). Brief report: Cool down: A procedure for decreasing ag gression in adults with traumatic head injury. Behavioral Residential Treatment, 6, 65-75.

Derby, K. M., Wacker, D. P., Sasso, G., Steege, M., Northrup, J., Cigrand, K., \& Asmus, J. (1992). Brief functional assessment techniques to evaluate aberrant behavior in an outpatient clinic: A summary of 79 cases. Journal of Applied Behavior Analysis, 25, 713-721.

Dobkin, P. L., \& Pihl, R. O. (1992). Measurement of psychological and heart-rate reactivity to stress in the real world. Psychotherapy and Psychosomatics, 58, 208-214. 
Fowles, D. C. (1982). Heart-rate as an index of anxiety: Failure of an hypothesis. In J. T. Cacioppo \& R. E. Petty (Eds.), Perspectives in cardiovascular psychophysiology (pp. 93-126). New York: Guilford Press.

Frankel, F., \& Simmons, J. Q. (1976). Selfinjurious behavior in schizophrenic and retarded children. American Journal of Mental Deficiency, 80, 512-522.

Gluck, J. P., Otto, M, W., \& Beauchamp, A. J., (1985). Respondent conditioning of selfinjurious behavior in early socially deprived rhesus monkeys. Journal of Abnormal Psychology, 94, 222-226.

Gottman, J. M. (1981). Time-series analysis: A comprehensive introduction for social scientists. New York: Cambridge University Press.

Gottman, J. M., \& Roy, A. K. (1990). Sequential analysis. New York: Cambridge University Press.

Guess, D., \& Carr, E., (1991). Emergence and maintenance of stereotypy and self-injury. American journal on Mental Retardation, 96, 335-344.

Halle, J. W., \& Gabler-Halle, D. (1989). Effects of a peer-mediated aerobic conditioning program on fitness measures with children who have moderate and severe disabilities. Journal of the Associations for Persons With Severe Disabilities, 14, 33-47.

Harris, J. C. (1992). Neurobiological factors in self-injurious behavior. In J. K. Luiselli, J. L. Matson, \& N. N. Singh (Eds.), Self-injurous behavior: Analysis, assessment, and treatment (pp. 93-121). New York: SpringerVerlag.

Hassett, J., \& Danforth, D. (1982). An introduction to the cardiovascular system. In J. T. Cacioppo \& R. E. Petty (Eds.), Perspectives in cardiovascular psychophysiology (pp. 418). New York: Guilford Press.

Homer, R, H. (1994). Functional assessment: Contributions and future directions. Journal of Applied Behavior Analysis, 27, 401-404.

Iwata, B. A., Pace, G. M., Dorsey, M. F., Zarcone, J. R., Vollmer, T. R., Smith, R. G., Rodgers, T. A., Lerman, D. C., Shore, B. A, Mazaleski, J. L., Goh, H., Cowdery, G. E., Kalsher, M. J., McCosh, K. C., \& Willis, K. D. (1994). The functions of self-injurious behavior: An experimental-epidemiological analysis. Journal of Applied Behavior Analysis, 27, 215-240.
Kantor, J. R. (1959). Interbebavioral psychology. Granville, $\mathrm{OH}$ : Principia Press.

Karsh, K. G., Repp, A. C., \& Ludewig, D. (1989). Portable computer systems for observational research: A software user's guide. DeKalb, IL: Communitech.

Kennedy, C. (1994). Automatic reinforcement: Oxymoron or hypothetical construct? Journal of Behavioral Education, 4, 387-395.

Leger, L., \& Thivierge, M. (1988). Heart-rate monitors: Validity, stability, and functionality. The Physician and Sports Medicine, 16, 143-151.

Lewis, M. H., MacLean, W. E., Johnson, W. L., \& Baumeister, A. A. (1981). Ultradian rhythms in stereotyped and self-injurious behavior. American Journal of Mental Deficiency, 85, 601-610.

Light, K. C., \& Obrist, P. A. (1980). Cardiovascular response to stress: Effects of opportunity to avoid shock experience, and performance feedback. Psychophysiology, 17, 243-252.

Mace, F.C., \& Mauk, J. E. (1999). Bio-behavioral diagnosis and treatment of self-injury. In A. C. Repp \& R. H. Horner (Eds.), Functional analysis of problem behaviors: From effective assessment to effective support (pp. 7897). Pacific Grove, CA: Brooks/Cole.

Manuck, S. B., \& Krantz, D. S. (1986). Psychophysiologic reactivity in coronary heart dis ease and essential hypertension. In K. A. Mathews, S. M. Weiss, T. Detre, T. M. Dembroski, B. Falkner, S. B. Manuck, \& R. B. Williams (Eds.), Handbook of stress, reactivity, and cardiovascular disease (pp. 1134). New York: Wiley.

Martin, G., \& Pear, J. (1988). Behavior modification. What it is and bow to do it (3rd ed.). Englewood Cliffs, NJ: Prentice Hall.

Newsom, C. D., Carr, E. G., \& Lovaas, O. I. (1977). The experimental analysis and modification of autistic behavior. In R. S. Davidson (Ed.), Modification of pathological behavior (pp. 109-187). Thousand Oaks, CA: Sage.

Obrist, P. A. (1976). The cardiovascular-behavioral interaction-as it appears today. Psychophysiology, 13, 95-107.

Obrist, P. A. (1982). Cardiac-behavioral interactions: A critical appraisal. In J. T. Cacioppo \& R. E. Petty (Eds.), Perspectives in cardiovascular psychophysiology (pp. 265-295). New York: Guilford Press.

Obrist, P. A., Webb, R. A., Sutterer, J. R., \& Howard, J. L. (1970). The cardiac-somatic relationship: Some reformulations. Psychophysiology, 6, 569-587.

O'Neill, R. E., Homer, R. H., Albin, R. W., Sprague, J. R., Storey, K., \& Newton, J. S. (1997). Functional assessment and program 
for problem behavior (2nd ed.). Pacific Grove, CA: Brooks/Cole.

Repp, A. C., \& Karsh, A. C. (1994). Laptop computer system for data recording and contextual analyses. In T. Thompson \& D. B. Gray (Eds.), Destructive behavior in developmental disabilities: Diagnosis and treatment (pp. 83-101). Thousand Oaks, CA: Sage.

Romanczyk, R. G. (1977, October). Treatment of self-injurious behavior and selfstimulatory behavior: The contrast between treatment and follow-up. Paper presented at the 24th annual meeting of the American Association on Mental Deficiency, Pittsfield, MA.

Romanczyk, R. G. (1987, October). Aversive conditioning as a component of comprehensive treatment: The impact of etiological factors on clinical decision making. Paper presented at Rutgers Symposium on Applied Psychology, New Brunswick, NJ.

Romanczyk, R. G. (1992, June). The role of arousal and anxiety in self-injurious behavior: Implications for treatment. Paper presented at the third international Fragile $\mathrm{X}$ Conference, Snowmass, CO.

Romanczyk, R. G., Gordon, W. C., Crimmins, D. B., Wenzel, A. M., \& Kistner, J. A. (1980). Childhood psychosis and 24-hour rhythms: A behavioral and psychophysiological analysis. Cbronobiologia, 7, 1-14.

Romanczyk, R. G., \& Goren, E. R. (1975). Severe self-injurious behavior: The problem of clinical control. Journal of Consulting and Clinical Psychology, 43, 730-739.

Romanczyk, R. G., Kistner, J. A., \& Plienis, A. (1982). Self-stimulatory and self-injurious behavior: Etiology and treatment. In J. Steffen \& P. Karoly (Eds.), Advances in child behavioral analysis and therapy: Vol. 2 (pp. 189-254). Lexington, MA: Lexington Books.

Romanczyk, R. G., Lockshin, S., \& O'Conner, J. 0. (1992). Psycho-physiology and issues of anxiety and arousal. In J. K. Luiselli, J. L. Matson, \& N. N. Singh (Eds.), Self-injurious behavior: Analysis, assessment and treatment (pp. 93-121). New York: SpringerVerlag.
Romanczyk, R. G., \& Mathews, A. L. (in press). Physiological state as antecedent: Utilization in functional analyses. In J. K. Luiselli \& M. J. Cameron (Eds.), Antecedent control procedures for the behavioral support of persons with developmental disabilities. Baltimore: Brookes.

Schroeder, S. R., \& Luiselli, J. K. (1992). Selfrestraint. In J. K. Luiselli, J. L. Matson, \& N. N. Singh (Eds.), Self-injurious behavior: Analysis assessment and treatment (pp. 293-306). New York: Springer-Verlag.

Schwartz, B. (1989). Psychology of learning and behavior (3rd ed.). New York: Norton.

Shapiro, D., \& Reeves, J. L. (1982). Modification of physiological and participative responses to stress through heart -rate and biofeedback. In J. T. Cacioppo \& R. E. Petty (Eds.), Perspectives in cardiovascular psychophysiology (pp. 127-150). New York: Guilford Press.

Tursky, B., \& Jamner, L. D. (1982). Measurement of cardiovascular functioning. In J. T. Cacioppo \& R. E. Petty (Eds.), Perspectives in cardiovascular psychophysiology (pp. 19-92). New York: Guilford Press.

Vollmer, T. R., Marcus, B. A., \& LeBlanc, L. (1994). Treatment of self-injury and handmouthing following inconclusive functional analyses. Journal of Applied Behavior Analysis, 27, 331-344.

Wahier, R. G., \& Graves, M. B. (1983). Setting events in social networks: Ally or enemy in child behavior therapy. Behavior Therapy, 14, 19-36.

Received 4/7/98, accepted 2/15/99.

This study was supported in part by The ARC of Washington Trust Fund and Grants No. H133B20004 and H029DO50063 from the US. Department of Education. However, the opinions expressed herein do not necessarily reflect the position or policy of either The ARC of Washington or the U.S. Department of Education, and no official endorsement should be inferred. Requests for reprints should be sent to Rachel Freeman, University Affiliated Program, 1052 Dole, University of Kansas, Lawrence, KS66045. 